\title{
The Necessity and Possibility of Transmission of Cultural Information in Metaphor and Simile
}

\author{
Yanping $\mathrm{Hu}$ \\ School of Foreign Languages, Southwest University for Nationalities, Chengdu 610041, China \\ 310786045@qq.com
}

Keywords: Metaphor, simile, necessity, possibility, transmission, cultural Information.

\begin{abstract}
Deeply rooted in their own culture, metaphor and simile demonstrate their own cultural flavor. Therefore the sense of metaphor and simile is frequently culture-specific. In view of deep cultural information of metaphor and simile, it is of great necessity for translators to convey the alien cultural information. Meanwhile, Eugene A. Nida has pointed out that at least ninety percent of fundamental structures of all languages are quite similar, and language universals far outweigh divergences. As a result, cultural exchange through translation is possible, though painstaking under certain circumstances. Many successful translations of metaphor and simile have also confirmed the possibility of transmitting their cultural information.
\end{abstract}

\section{Introduction}

Logan Pearsall Smith has ever said, "Most of our figurative expressions are created by common people, resulting from the careful observation on their jobs and hobbies" [1]. In other words, it is the common people who create the figurative language. Blacksmith will say "strike while the iron is hot"; teachers could teach students "more haste, less speed"; fishermen know how "to pass fish eyes for pearls" while sailors feel frightened with something "overhead and ears". Since the figurative language is mostly from common people, it can exactly and truly reflect features of a race, and its economy, customs and psychology. Therefore, it is necessary to transmit the cultural information of metaphor and simile in translation. Meanwhile, with more and more cultural exchange, translators are obviously confronted with the translation of metaphor and simile. No matter how painstaking it is, many successful translations have confirmed the possibility of transmitting the cultural information.

\section{The Relation of Metaphor, Simile and Culture}

Deeply rooted in their own culture, metaphor and simile are marked with national and cultural characteristics. In different cultures, different languages conceptualize and create symbols in varying ways, and therefore the sense of metaphor and simile is frequently culture-specific [2]. In view of different cultures, different tenors and vehicles are employed in both languages. Sometimes it's by no means easy to translate those cultural-specific words. For example, "as wise as an owl" indicates that English-speaking people associate wisdom with this bird. In Children's books and cartoons, the owl is usually solemn and wise. In disputes among birds and beasts, it is the owl that acts as judge. In moments of crisis, it is the owl that they go to for advice. Sometimes the bird is considered as impractical and foolish, but in the main, the owl stands for wisdom. Among Chinese, however, there is a superstitious belief that this bird is a sign of bad luck. There is a saying "an owl visiting a home", portending misfortune in that household. The mere sight of an owl or the sound of the creature's hooting is enough to cause people to draw back in fear. Another example, "talk/speak of the devil and he will appear." We couldn't find any traces of the name Cao Cao in English due to different histories. Chinese people know clearly that Cao Cao is a national figure in the Chinese history. It's also a symbol, which represents certain features of Chinese culture. However, the translation fails to introduce these to westerners, except that he is a "devil". These two examples show that obstruction in translation mainly comes from cultural differences. As Dagut puts it, what determines the translatability of a source language metaphor is not its "boldness" or "originality", but rather the 
extent to which the cultural experience and semantic association on which it draws are shared by speakers of the particular target language [3]. Take "Ren Shen Guo" for example. It is a magic fruit which symbolizes immortality. Originating from Chinese mythology, "Ren Shen Guo" has no counterpart in English. Thus, "Ren Shen Guo" seems untranslatable due to cultural differences. However, with a view to introducing its cultural connotations, translators wittily employ such a technique as "translation plus explanation". As a result, "Ren Shen Guo" is rendered into "Ren Shen Guo" (a fruit of immortality). Therefore, it's necessary and possible to transmit the cultural information of metaphor and simile.

\section{The Necessity of Transmission of Cultural Information in Metaphor and Simile}

In view of deep cultural connotations of metaphor and simile, it is necessary for translators to convey their cultural connotations. For example, Li Shangyin, a celebrated poet in Tang Dynasty, has ever written a famous sentence "The silkworm till its death spins silk". In this sentence, the poet describes the love-sick feeling as the silk spun from the silkworm which keeps spinning until it dies. We Chinese people appreciate silkworms because in the long history of China, we have been keeping silkworms to get silk and make clothes. Although the silkworm, from its appearance, is not attractive, it appears often in Chinese poems, expressing good feelings. The English people, who don't have such a tradition and know little about the silkworm, may wonder why love-sick feeling can be aroused by the silkworm. Therefore, it is of great necessity for translators to transmit the cultural connotations of silkworm to target readers. As a matter of fact, "silk" and"love-sick"express a sort of endless yearning of man that only ends in the death. Through the image of the spring silkworm, the tenderness that is engraved on one's heart was expressed more vividly and forcefully moving. The key to the verse is how to accurately transmit the cultural connotation of the silkworm to target readers. Let's appreciate the version by Xu Yuanchong: "The silkworm till its death spins silk from love-sick heart [4]." Obviously his version vividly and faithfully embodies the cultural connotations of silkworm.

In Shakespeare's Sonnet 18, he compares his friend to a summer's day. Because of the geographical environment in England, summer is the most amicable and pleasant one in four seasons [5]. However, in China, summer appears too hot and unbearable. Thus, Chinese people can hardly arouse any good feeling from such a comparison. Some scholars argue that we can substitute the spring's day for the summer's day in favor of target readers' understanding. However, as Peter Newmark puts it, target readers with their own imagination are able to enjoy an exotic culture in translation. Xu Jun, a contemporary Chinese translator, once conducted a research with questionnaires, whose result showed that the target language readers preferred to read translations with wellpreserved exotic flavor. This is a natural desire arising from the readers' aesthetic appreciation. People travel to other countries for experiencing an obviously exotic atmosphere. This is also true with translation. Lu Xun, a Chinese literary master of the $20^{\text {th }}$ century, pointed out, "The exotic appeal must be well kept in translation so as to preserve the graceful airs of the original work" [6]. Let's take Yang's version for example: Even the cleverest housewife can't cook a meal without rice [7]. Such a translation keeps the image and accords with the whole cultural atmosphere of the novel-A Dream of Red Mansions. Although "Even the cleverest housewife can't make bread without flour" can convey the same pragmatic meaning, the use of "bread" and "flour" damage the cultural atmosphere of the whole text. What's more, Yang's version conveys such cultural information that in China people have rice instead of bread. To sum up, translation as a bridge between different countries will undoubtedly bear the responsibility of conveying the alien cultural information.

\section{The Possibility of Transmission of Cultural Information in Metaphor and Simile}

As we know, culture is an extremely complex concept and an enormous subject. It almost embraces everything in the world, whether material or spiritual. However complex it is, the acceptance or transmission of culture is possible. Translation has been instrumental in transmitting cultures. Closely linked with culture, metaphor and simile are characterized by their national and cultural color. In order to translate accurately, translators should aim to convey the cultural information of metaphor 
and simile. Meanwhile, according to Eugene A. Nida, at least ninety percent of fundamental structures of all languages are quite familiar, and language universals far outweigh divergences. All languages employ figurative expressions [8]. As a result, there appear some similar metaphors and similes in two languages. Therefore, cultural exchange through translation is possible, though painstaking under certain circumstances. Many successful translations of metaphor and simile have also confirmed the possibility of transmitting their cultural information. Let's take "Sai Wong Shi Ma, An Zhi Fei Fu" for example.

Version 1: The loss of the old man's horse at the border country was not actually a blessing?

Version 2: Misfortune may prove a business in disguise.

Version 3: When the old man at the frontier lost his horse, he thought it might be a good thing.

Note: An allusion to a story popular for more than 2000 years in China. When an old man lost his horse, neighbors condoled with him.

"This may be a good thing," he said.

The horse came back with another horse, and the old man's neighbor congratulated him.

"This may prove unlucky," he said.

When his son, who liked the new horse, rode it and broke his leg, once more the neighbors expressed his sympathy.

"This may turn out for the best," the old man said.

And, indeed, just then the Huns invaded the country and almost able-bodied men were conscripted and killed in battle, but thanks to his broken leg the old man's son survived. [5]

Version 1 was done in the 1940s, when few Chinese literary works were translated into foreign languages and most westerners knew nothing about China. The translator rendered the metaphorical expression directly without any note or explanation. His version is by no means good. Version 2 was done after liberation when cultural exchange was conducted more frequently than before. The translator resorts to the ready English expressions, easy to understand but losing the unique Chinese image. Their translation has not contributed to promoting readers' awareness of cultural differences. Version 3 is a relatively satisfactory one, in the sense that it keeps the original image yet at the same time gives a note to help the readers' understanding. Maybe after years of cultural communication, it is no longer necessary for such a note to be added. Westerners will not only understand the idioms, but will also have the same association as Chinese do. In a word, these successful translations have proved the feasibility of conveying the cultural information of metaphor and simile.

\section{Conclusion}

Nowadays, since the global village is becoming smaller and smaller, people on the earth long for knowing more about foreign culture. The readers' cultural version has to a large extent been enlarged; the cultural exchange and readers' reception screen are widened. Transmission of cultural information will meet the readers' needs to taste exotic beauty and help them enjoy the uniqueness of an alien culture. Therefore, translators spare no efforts in conveying the cultural information of the source language. Meanwhile, a large amount of successful translations of metaphor and simile have also confirmed the possibility of transmitting the cultural information. To sum up, in the translation of metaphor and simile, it's necessary and possible for translators to transmit their cultural information.

\section{Acknowledgements}

This work is supported by Fundamental Research Funds for the Central Universities, Southwest University for Nationalities (No. 2016SZYQN43).

\section{References}

[1]. Smith, Longan Pearsall. Words and Idioms. Constable \& Company Ltd, 1943, p. 10.

[2]. Mary, Snell-Hornby. Translation Studies-An Integrated Approach. Shanghai Foreign Language Education Press, 2001, p. 56. 
[3]. Dagut, M.B. “Can Metaphor be Translated?” in Bable, Vol. 22. No.1, 1976, p. 21-33.

[4]. Yuanchong Xu. Version of Classical Chinese Poetry. Dolphin Publishing House, 2015, p.126.

[5]. Jingyu Bai. Language and Culture. China Social Sciences Press, 2000, p. 6.

[6]. Xun Lu. Untitled. On Translation Studies. The Commercial Press, 1984, p. 86, p. 46-47.

[7]. Xianyi Yang \& Gladys Yang. A Dream of Red Mansions. Foreign Languages Press, 2009, p. 656-657.

[8]. Nida, Eugene. Language, Culture and Translation. Shanghai Foreign Language Education Press, 1993, p. 106. 